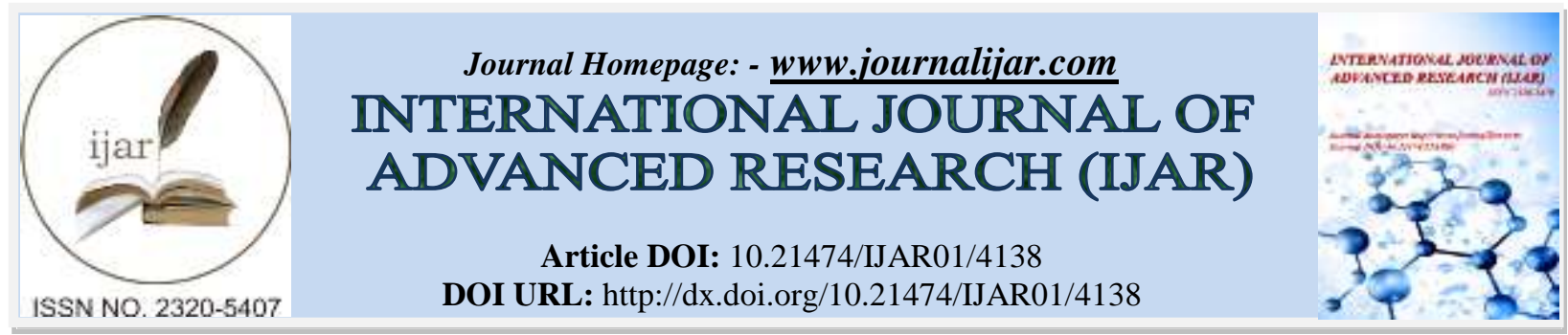

RESEARCH ARTICLE

\title{
A STUDY ON PREVALENCE OF VITAMIN D DEFICIENCY IN SOFT WARE PREGNANT WOMEN AND THE FETO MATERNAL OUTCOME.
}

Golla Shanti Sneha and Hima Bindu V.

\section{Manuscript Info}

-.........................

Manuscript History

Received: 05 March 2017

Final Accepted: 04 April 2017

Published: May 2017

Key words:-

25(OH)D) : 25hydroxy vitamin D, Ca :

calcium, Software women, Pregnancy.

\section{Abstract}

Background: Vitamin D deficiency was associated with the pathogenesis of several chronic disorders of human beings. An increasing number of studies were correlating the role of vitamin D deficiency and feto maternal outcomes. The aim of this study was to determine the prevalence of vitamin D deficiency among the pregnant women working in software offices and its impact on the fetal and maternal outcome.

Methods: A cross sectional study was conducted in 150 pregnant women attending Femina womens hospital Hyderabad, for a period of 6 months from October 2015 to April 2016. The aim was to study the prevalence of vitamin D deficiency in pregnant women working in software offices. The women were given a questionnaire consisting of data regarding occupation, obstetric history, lifestyle ,dietary habits ,working hours. Serum 25hydroxy vitamin D (25(OH)D) level was measured using an enzyme immunoassay method. Data on gestational age ,mode of delivery ,baby sex , weight of baby were studied.

Results: Mean age of the study population was $27.4 \pm 3.1$ years in soft ware group and $28.2 \pm 2.9$ years in non soft ware group. Over all the prevalence of vitamin D deficiency was $56 \%$ and severe deficiency was observed in $16 \%$ s among pregnant women in this study. The vitamin D serum levels were significantly lower in the soft ware group $(\mathrm{p}=0.03)$ and severe deficiency was also more common in the soft ware group $(p=0.04)$. There was no statistically significant difference between the two groups with respect to the total number of maternal and fetal complications.

Conclusion: Vitamin D concentrations were observed to be low in Soft ware pregnant women when compared with non soft ware pregnant women without any significant differences in feto maternal outcomes.

Copy Right, IJAR, 2017,. All rights reserved.

\section{Introduction:-}

Vitamin D is an essential fat-soluble vitamin that is required for regulation of calcium metabolism. Vitamin D orchestrates the "Ca-vitamin D-Parathyroid hormone endocrine axis . Vitamin D and its metabolites are hormones and hormone precursors rather than vitamins. It is unique among vitamins - made in the skin from exposure to sunlight. Vitamin D deficiency has long been associated with poor bone development and has been identified as the cause of rickets in growing children and osteomalacia in adults. With abundant sunlight, Vitamin D deficiency was considered to be rare in India ${ }^{1}$. Vitamin D deficiency has been reported in all age groups including toddlers, school 
children, pregnant women and their neonates and adult males and females residing in rural and urban India ${ }^{\mathbf{2 , 3}}$.The prevalence and additional consequences of low serum vitamin D levels have not been recognized until recently. Vitamin D deficiency during pregnancy was a worldwide epidemic studies show a prevalence range from 18$84 \%$. Pregnant women in India have shown a prevalence of vitamin D deficiency of 84 per cent which correlated

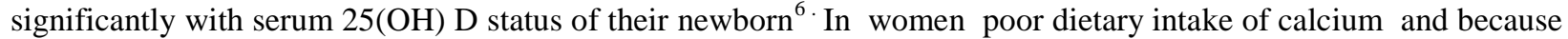
of the active transplacental transport of calcium to the developing fetus which is likely to worsen during pregnancy ${ }^{6}$.

\section{Vitamin D physiology:-}

Vitamin D is a prohormone that is derived from cholesterol. The nutritional forms of vitamin D include D3 (cholecalciferol), which is generated in the skin of humans and animals, and vitamin D2 (ergocalciferol), which is derived from plants; both forms can be absorbed in the gut and used by humans. Vitamin $\mathrm{D}_{2}$ is found in foods such as cod-liver oil, fatty fish, and egg yolk. Casual exposure to solar radiation wavelengths 290-315 nm results in the cutaneous production of previtamin $\mathrm{D}_{3} .{ }^{7}$ The efficiency of vitamin $\mathrm{D}$ synthesis depends on a variety of factors, most importantly the number of UVB photons that penetrate the epidermis. More time spent indoors and widespread use of sunscreen have resulted in reduced sun exposure and less vitamin D production ${ }^{8}$. During sun exposure the UVB photons (290-315 nm) that enter the epidermis cause a photochemical transformation of 7-dehydrocholesterol (7DHC) (provitamin $\mathrm{D}_{3}$ ) to previtamin $\mathrm{D}_{3}$. The percent conversion of 7-DHC to previtamin $\mathrm{D}$ and its photoproducts and percent of previtamin D and vitamin D formed was maximal between 11 a.m. to 2 p.m ${ }^{9}$. Physiologically Vitamin D3 and Vitamin D2 are bound to the vitamin D- binding protein (VDBP) in plasma and transported to the liver to become 25-hydroxy vitamin D (Vitamin D (25-OH)). As Vitamin D (25-OH) represents the major storage form, its blood concentration is used to assess the over all Vitamin D status ${ }^{10}$. More than $95 \%$ of Vitamin D $(25-\mathrm{OH})$, measurable in serum is Vitamin D3 (25-OH) whereas Vitamin D2 (25$\mathrm{OH})$ reaches measurable levels only on patients taking Vitamin D2 supplements.

Vitamin D status is usually estimated by measuring the levels of plasma $25(\mathrm{OH}) \mathrm{D}$ levels the major storage form of vitamin D. Studies have developed a classification of stages for vitamin D status in non pregnant adults that indicate that levels $>30 \mathrm{ng} / \mathrm{ml}$ are required for adequacy ${ }^{11}$. During pregnancy and lactation, significant changes in maternal vitamin $\mathrm{D}$ and calcium metabolism occur to provide the calcium that is needed for fetal bone mineral accretion these stages correlate with maternal and fetal outcomes, which suggests that they also apply in pregnancy and during lactation $^{.11}$

\begin{tabular}{|l|l|l|l|}
\hline Stage & $\begin{array}{l}\text { Serum } \\
25(\mathrm{OH}) \mathrm{D}, \mathrm{ng} / \mathrm{ml}\end{array}$ & Maternal adverse effects & New born infant adverse effects \\
\hline $\begin{array}{l}\text { Severe } \\
\text { deficiency }\end{array}$ & $\leq 10$ & $\begin{array}{l}\text { Increased risk of preeclampsia, bone loss } \\
\text {,malabsorption, myopathy, weight gain, } \\
\text { higher parathhormones }\end{array}$ & $\begin{array}{l}\text { Small for gestational age, } \\
\text { neonatal hypocalcemic seizures, } \\
\text { infantile heart failure large } \\
\text { frontanelle, congential rickets, } \\
\text { enamel defects }\end{array}$ \\
\hline Insufficiency & $11-29$ & Bone loss, subclinical myopathy & $\begin{array}{l}\text { Neonatal hypocalcemia, reduced } \\
\text { bone mineral density, rickets of } \\
\text { infancy if breast feed }\end{array}$ \\
\hline Adequacy & $30-100$ & Adequate calcium balance & None \\
\hline Toxicity & $>100$ & $\begin{array}{l}\text { Hypercalcemia, increased urine calcium } \\
\text { loss }\end{array}$ & $\begin{array}{l}\text { Infantile } \\
\text { hypercalcemia }\end{array}$ \\
\hline
\end{tabular}

\section{Table 1:-}

There are very few studies reporting the vitamin D deficiency in soft ware pregnant women. The present study was conducted to investigate the prevalence of vitamin D deficiency among software pregnant women. We conducted this study in Hyderabad, one of the soft ware hubs in India.

\section{Methods:-}

Between October 2015 and April 2016, 150 apparently healthy pregnant women attending the outpatient department were included in this study. This cross sectional study was conducted at Femina womens hospital Hyderabad. The aim was to study the prevalence of vitamin D deficiency in pregnant women working in software offices. The maternal and fetal outcome were also studied in both the groups. During the study period, all the pregnant women 
attending the outpatient for the $1^{\text {st }}$ consultation irrespective of the gestational age were considered in the study after taking a written and informed consent.

Women with any previous medical disorders were excluded from the study. Subjects with known hepatic or renal disease, metabolic bone disease, malabsorption, type 1 diabetes, hypercortisolism, and those already on therauptic Vitamin D supplementations were not included in the study.

The pregnant women were given the questionnaire which covered obstetric history, lifestyle, dietary habits. Blood samples were collected irrespective of the season of the year. Blood samples were centrifuged and stored at $-20^{\circ} \mathrm{C}$.

The analysis was done by Elecsys, Chemiluminescence method (Competitive protein binding assay) on cobas e411, (Roche). The laboratory reference range below $10 \mathrm{ng} / \mathrm{ml}$ is considered as deficiency, $10-30 \mathrm{ng} / \mathrm{ml}$ is insufficiency and levels between $30-70 \mathrm{ng} / \mathrm{ml}$ is optimum for serum total Vitamin D. Data regarding the Gestational age of delivery, baby sex, birth weight, mode of delivery were collected. We divided pregnant women in each group into two subgroups like those with low vitamin D levels less than $30 \mathrm{ng} / \mathrm{ml}$ as one group and those with more than $30 \mathrm{ng} / \mathrm{ml}$ as other group. Statistical analysis was done by SSS(social science statistics ) software and $p$ value $\leq 0.05$ was considered as significant. Proportions were compared by using the chisquare test.

\section{Results:-}

During the Study period 150 pregnant women attended the outpatient clinic and among them 60 women were working at the soft ware companies remaining 90 women had different other occupations. Mean age of the study population was $27.4 \pm 3.1$ years in soft ware group and $28.2 \pm 2.9$ years in non soft ware group with $70 \%$ of the soft ware group were primi gravida and only $53.3 \%$ were primi gravida in non software group. Over all the prevalence of vitamin D deficiency was $56 \%$ and severe deficiency was observed in $16 \%$ s among pregnant women in this study .

Table 2:- Gestational age at the time of $1^{\text {st }}$ consultation:

\begin{tabular}{|l|l|l|l|}
\hline Gestational age & Software $(\mathrm{n}=60)$ & Non Software $(\mathrm{n}=90)$ & $\mathrm{p}$ value \\
\hline 1 st trimester & $38(63.3 \%)$ & $63(70 \%)$ & 0.393 \\
\hline 2 nd trimester & $17(28.3 \%)$ & $19(21.2 \%)$ & 0.310 \\
\hline rd trimester & $5(8.33 \%)$ & $8(8.88 \%)$ & 0.905 \\
\hline
\end{tabular}

Chi square test $(\mathrm{p} \leq 0.05)$

Table 3:- Vitamin D levels:

\begin{tabular}{|l|l|l|l|}
\hline Vitamin D levels & Software $(\mathrm{n}=60)$ & Non software $(\mathrm{n}=90)$ & $\mathrm{p}$ value \\
\hline Normal $(\geq 30 \mathrm{ng} / \mathrm{ml})$ & $20(33.3 \%)$ & $46(51.11 \%)$ & 0.031 \\
\hline Insufficient $(11-29 \mathrm{ng} / \mathrm{ml})$ & $26(43.3 \%)$ & $34(37.8 \%)$ & 0.496 \\
\hline Deficiency $(\leq 10 \mathrm{ng} . \mathrm{ml})$ & $14(23.3 \%)$ & $10(11.1 \%)$ & 0.045 \\
\hline
\end{tabular}

Chi square test $\quad(\mathrm{p} \leq 0.05)$

There was no significant difference between soft ware and non software group with respect to the gestational age at the time of sample collection. The vitamin D serum levels were significantly lower in the soft ware group $(\mathrm{p}=0.03)$ and severe deficiency was also more common in the soft ware group $(\mathrm{p}=0.04)$ however there was no significant difference between two groups with vitamin D insufficiency.

Table 4:- Maternal complications according to Vitamin D levels:

Soft ware

\begin{tabular}{|l|l|l|l|l|l|l|l|}
\hline & $\begin{array}{l}\text { Normal } \\
\text { vitamin D } \\
(\mathrm{n}=20)\end{array}$ & $\begin{array}{l}\text { Insufficient } \\
(\mathrm{n}=26)\end{array}$ & $\begin{array}{l}\text { Deficient } \\
(\mathrm{n}=14)\end{array}$ & $\begin{array}{l}\text { Normal } \\
\text { vitamin } \\
\mathrm{D}(\mathrm{n}=46)\end{array}$ & $\begin{array}{l}\text { Insufficient } \\
(\mathrm{n}=34)\end{array}$ & $\begin{array}{l}\text { Deficient } \\
(\mathrm{n}=10)\end{array}$ & P value \\
\hline No complications & $18(90 \%)$ & $23(88.5 \%)$ & $12(85.7 \%)$ & $40(87 \%)$ & $29(85.3 \%)$ & $7(70 \%)$ & \\
\hline GDM & 0 & 0 & 0 & 3 & 1 & 0 & \\
\hline PIH & 1 & 2 & 0 & 0 & 2 & 1 & \multirow{2}{*}{501} \\
\cline { 1 - 5 } Oligohydramnios & 1 & 1 & 1 & 2 & 2 & 1 & \\
\hline Preterm & 0 & 0 & 1 & 1 & 0 & 1 & \\
\hline
\end{tabular}




\begin{tabular}{|l|l|l|l|l|l|l|l|}
\hline Abruptio placenta & 0 & 0 & 0 & 0 & 0 & 0 & \\
\hline $\begin{array}{l}\text { Total } \\
\text { complications }\end{array}$ & $2(10 \%)$ & $3(11.5 \%)$ & $2(14.3 \%)$ & $6(13 \%)$ & $5(14.7 \%)$ & $3(30 \%)$ & \\
\hline
\end{tabular}

Table 5:- .Fetal complications

\begin{tabular}{|c|c|c|c|c|c|c|c|}
\hline \multicolumn{3}{|c|}{ Soft ware } & \multicolumn{4}{|c|}{ Non soft ware } & \\
\hline Complication & $\begin{array}{l}\text { Normal } \\
\text { vitamin } \quad D \\
(\mathrm{n}=20)\end{array}$ & $\begin{array}{l}\text { Insufficient } \\
(\mathrm{n}=26)\end{array}$ & $\begin{array}{l}\text { Deficient } \\
(\mathrm{n}=14)\end{array}$ & $\begin{array}{l}\text { Normal } \\
\text { vitamin D } \\
(\mathrm{n}=46)\end{array}$ & $\begin{array}{l}\text { Insufficient } \\
(\mathrm{n}=34)\end{array}$ & $\begin{array}{l}\text { Deficient } \\
(\mathrm{n}=10)\end{array}$ & $\mathrm{p}$ value \\
\hline \multirow{3}{*}{$\begin{array}{l}\text { Birth weight } \\
<2.5 \mathrm{~kg} \\
2.5-3.5 \mathrm{~kg} \\
>3.5 \mathrm{~kg} \\
\end{array}$} & 1 & 1 & 4 & 1 & 4 & 1 & \\
\hline & 9 & 24 & 9 & 35 & 27 & 7 & \\
\hline & 10 & 1 & 1 & 8 & 3 & 2 & 0.460 \\
\hline $\begin{array}{l}\text { NICU } \\
\text { admission }\end{array}$ & 1 & 2 & 1 & 1 & 1 & 1 & 0.343 \\
\hline IUGR & 0 & 0 & 1 & 1 & 0 & 0 & 0.771 \\
\hline
\end{tabular}

There was no statistically significant difference between the two groups with respect to the total number of maternal and fetal complications.

\section{Discussion:-}

The reported paradox of the prevalence of vitamin D deficiency in the sun-abundant South Asian countries remains unexplained. The prevalence of vitamin D deficiency was influenced by ethnicity, food habits, dietary supplements, food fortification, clothing, climate, atmospheric pollution, season of the year and duration of exposure to sun light. Recent reports of low $25(\mathrm{OH}) \mathrm{D}$ concentrations in healthy subjects resident in India ${ }^{12}$. Hypo vitaminosis D among pregnant Indian women had been widely reported ${ }^{3,6}$. The prevalence of vitamin D deficiency was $56 \%$ in our study and severe deficiency was observed in $16 \%$ among pregnant women in this study which was less than to a study published by Marwaha $\mathrm{K}^{13}$ et al and Sachan A et $\mathrm{al}^{6}$. Various other studies by Kovacs et ${ }^{14}$ al et al and Choi $\mathrm{R}$ et $\mathrm{al}^{15}$ had shown that the prevalence of vitamin D deficiency is ranging $5-50 \%$ in mothers.

Also, to the best of our knowledge, this was the first report of vitamin D status that represents the Soft ware pregnant women who spend more time in air conditioned rooms with low exposure to sun light in a tropical country. The results of the study confirms the high prevalence of vitamin D deficiency (21.6\%) and insufficiency (43.35\%) among soft ware pregnant women when compared to non soft ware pregnant women $(11.1 \%$ deficiency and $37.8 \%$ insufficiency) of similar gestational age. Since there was a positive correlation between sunlight and Vitamin D status ${ }^{9,14}$ the observed decrease in Vitamin D concentration and deficiency in soft ware pregnant women can be attributed to sedentary indoor lifestyle in which there was less exposure to sun and more frequent use of sunscreens. Another possible reason of Vitamin D deficiency in soft ware pregnant women was attributable to diets that were not rich in Vitamin D with poor dietary absorbable calcium content.

The impact of vitamin D deficiency during pregnancy on maternal and neonatal health has attracted much controversy in recent years. However, a causal link between vitamin D deficiency during pregnancy and adverse pregnancy-related outcomes remains to be determined, one meta-analysis supported a possible link between a low $25(\mathrm{OH}) \mathrm{D}$ status and poor neonatal outcomes ${ }^{17}$, the precise mechanisms underlying this association are yet to be determined. A recent systematic review and meta-analysis found that spontaneous preterm birth and childbirth with SGA were significantly associated with $25(\mathrm{OH}) \mathrm{D}$ levels $<20 \mathrm{ng} / \mathrm{mL}^{18}$.

In our study we did not found any significant difference between the two groups with respect to the total number of maternal and fetal complications similarly Rodriguez et al $^{19}$ did not find any association between maternal circulating 25(OH)D3 concentration in pregnancy with GDM and preterm delivery. In our study the serum vitamin $\mathrm{D}$ levels in both the groups had no impact on the neonatal birth weight. Similarly in a study published by Maryam et $\mathrm{al}^{20}$ and Maghbooli et al ${ }^{21}$ suggested that there was no significant association of birth weight with serum vitamin $\mathrm{D}$ levels. Heather H. Burris et al ${ }^{22}$ did not found any association with serum vitamin D levels and hypertensive disorders in pregnancy, in the present study also there was no significant difference between two groups with respect to pregnancy induced Hypertension. Although it was not clear whether maternal vitamin D supplementation will prevent these conditions, a strategy for supplementation and treatment of maternal vitamin D deficiency was 
proposed $^{23}$. Further studies with large number of study participants are required to study the effects of vitamin D supplementation and feto maternal outcomes .

\section{Conclusion:-}

Vitamin D concentrations were observed to be low in Soft ware pregnant women in all the three trimesters when compared with non soft ware pregnant women with out any significant differences in feto maternal outcomes between soft ware and non software women.

Conflict of interest: The authors declare no conflict of interest

\section{References:-}

1. C.V. Harinarayan, T. Ramalakshmi, U.V. Prasadet al: Vitamin D status in Andhra Pradesh : A population based study. Indian J Med Res 127, March 2008, pp 211-218.

2. Geeta Trilok Kumar, Reema Chugh , and Manfred Eggersdorfer : Poor Vitamin D Status in Healthy Populations in India: A Review of Current Evidence. Int. J. Vitam. Nutr. Res., 85 (3 - 4), 2015, 185 - 201.

3. Ravinder Goswami, Nandita Gupta, Deepti Goswami,et al. Prevalence and significance of low 25hydroxyvitamin D concentrations in healthy subjects in Delhi. Am J Clin Nutr 2000;72:472-5.

4. Holick MF, Chen TC. Vitamin D deficiency: A worldwide problem with health consequences. Am J Clin Nutr. 2008;87:1080S-6S.

5. Dawodu A, Wagner CL. Mother-child vitamin D deficiency: an international perspective. Arch Dis Child. 2007;92:737-40.

6. Sachan A, Gupta R, Das V, Agarwal A,et al. High prevalence of vitamin D deficiency among pregnant women and their newborns in northern India. Am J ClinNutr. $200581:$ 1060-4.

7. Holick MF Vitamin D deficiency. N Engl J Med 357: 266-281. 2007.

8. Ritu G and Ajay Gupta : Vitamin D Deficiency in India: Prevalence, Causalities and Interventions . Nutrients. 2014 Feb; 6(2): 729-775 .

9. CV Harinarayan, Shashank R Joshi: Vitamin D Status in India - Its Implications and Remedial Measures. J Assoc Physicians India. 2009 Jan;57:40-8.

10. Megan L. Mulligan, BA, Shaili K. et al. Implications of vitamin D deficiency in pregnancy and lactation. Am J Obstet Gynecol. 2010 May ; 202(5): 429.e1-429.e9.

11. Ross AC, Manson JE, Abrams SA, Aloia JF, Brannon PM, Clinton SK. The 2011 report on dietary reference intakes for calcium and vitamin D from the institute of medicine: what clinicians need to know. J Clin Endocrinol Metab. 2011;96:53-58.

12. Sahu M, Bhatia V, Aggarwal A et al. Vitamin D deficiency in rural girls and pregnant women despite abundant sunshine in northern India. Clin Endocrinol (Oxf). 2009 May;70(5):680-4.

13. Marwaha K, Tandon N, Chopra S et al . Vitamin D status in pregnant Indian women across trimesters and different seasons and its correlation with neonatal serum 25-hydroxyvitamin $\mathrm{D}$ levels. $\mathrm{Br} \mathrm{J}$ Nutr. 2011;106:1383-9.

14. Kovacs C. Calcium and Bone Metabolism in Pregnancy and Lactation. The Journal of Clinical Endocrinology Metabolism. 2001;86(6):2344-2348.

15. Choi R, Kim S, Yoo H, et al. High Prevalence of Vitamin D Deficiency in Pregnant Korean Women: The First Trimester and the Winter Season as Risk Factors for Vitamin D Deficiency. Nutrients. 2015;7(5):3427-3448.

16. Hart GR, Furniss JL, Laurie D, Durham SK : Measurement of vitamin D status: background, clinical use, and methodologies. Clin Lab 52: 335-343.2006.

17. Aghajafari F., Nagulesapillai T., Ronksley P.E., Tough S.C., O’Beirne M., Rabi D.M. Association between maternal serum 25-hydroxyvitamin D level and pregnancy and neonatal outcomes: Systematic review and metaanalysis of observational studies. BMJ Clin. Res. Ed. 2013;346:f1169.

18. Wei S.Q., Qi H.P., Luo Z.C., Fraser W.D. Maternal vitamin D status and adverse pregnancy outcomes: A systematic review and meta-analysis. J. Matern. Fetal Neonatal Med. 2013;26:889-899.

19. Rodriguez,R García-Esteban,M Basterretxea et al .Associations of maternal circulating 25 hydroxyvitamin D3 concentration with pregnancy and birth outcomes.BJOG 11 September 2014:10.1111/1471-0528.13074.

20. Maryam Abbasian, Reza Chaman,et al.Vitamin D Deficiency in Pregnant Women and Their Neonates. Glob J Health Sci. 2016 Sep; 8(9): 83-90.

21. Maghbooli Z, Hossein-Nezhad A,Shafaei A. R et al. Vitamin D status in mothers and their newborns in Iran.BMC pregnancy and childbirth. 2007;7(1)-1 
22. Heather H. Burris,Sheryl L. Rifas-Shiman,Susanna Y. Huh et al. Vitamin D Status and Hypertensive Disorders in Pregnancy. Ann Epidemiol. 2014 May ; 24(5): 399-403.

23. Yu CK, Sykes L, Sethi M, Teoh TG, Robinson S. Vitamin D deficiency and supplementation during pregnancy. Clin Endocrinol (Oxf). 2009;70:685-90. 